\title{
Analysis of the possibility of utilization of waste heat from the marine engine in the ORC power plant
}

\author{
Radomir Kaczmarek ${ }^{1}$, and Aleksander Stachel ${ }^{1, *}$ \\ ${ }^{1}$ West-Pomeranian University of Technology, Szczecin, Department of Heat Enginnering, al. Piastów 17, PL-70-310 Szczecin, Poland
}

\begin{abstract}
Modern marine diesel engines are characterized by $\sim 50 \%$ conversion of chemical energy of fuel into useful work. The remaining amount of heat is lost to the environment as the so-called waste heat, whereby its part can be used in various marine heating installations. In the ship's engine the biggest source of waste heat, potentially useful for further use, both due to the amount of available energy and its quality, are exhaust emissions from the main engine. Taking into account the need for rational energy management, the paper presents a preliminary analysis and assessment of the possibility of using the heat of hot exhaust gases to generate electricity in the so-called low-temperature ORC installation. Based on the available data, the operation of ORC installation has been evaluated, taking into account the influence of engine operating parameters on the obtained electrical power and the cycle efficiency. The aim of the analysis was to demonstrate that there is a real possibility to use the waste heat from marine engine exhausts to drive the ORC and generate electricity.
\end{abstract}

\section{Introduction}

The naval power plant is consisting of a set of machines and devices generating various forms of energy necessary to fully meet the ship's energy demand, which in sea conditions must be a self-sufficient unit in this respect. On the ship, the useful energy is obtained as a result of conversion of chemical energy of fuels. As a result mechanical, electric and thermal energy is generated .

Due to its duties, the naval power plant is divided into:

- principal power station, the main part of which is the major engine, and its task is to generate mechanical energy for the propulsion of the ship (e.g. propulsion of the propeller shaft);

- auxiliary power plant, the purpose of which is to generate energy necessary for the operation of devices and mechanisms servicing the main propulsion system, as well as all other devices and receivers installed on the ship.

Due to the used solutions, the power plants are divided into combustion, steam and combined plants, for example, combustion-steam ones.

One of the most commonly used types of main propulsion are reciprocating diesel engines, also used in generating sets and other ship equipment. Main propulsion engines are built as high-pressure, two-stroke, low-speed or as high-pressure, four-stroke, mediumspeed ones. Both groups are adapted to burning diesel fuels and the so-called heavy fuels. In addition to piston engines, ship turbines also use steam turbines and gas turbines (turbogas power plants).
An important element of the main engine operation, including the entire engine room, is the rationalization of fuel consumption, which translates into, among others, reduction of costs and reduction of emissions. The cutback on fuel consumption can be achieved by improving the energy efficiency of the power station and other ship equipment, as well as the utilization of the socalled waste energy (heat). Due to the amount of power generated, this applies in particular to the main propulsion engine (Fig. 1). The heat contained in the exhaust gases leaving the engine, as well as in other heat carriers, such as cooling water and charge air, can be used for various purposes, e.g. heating.

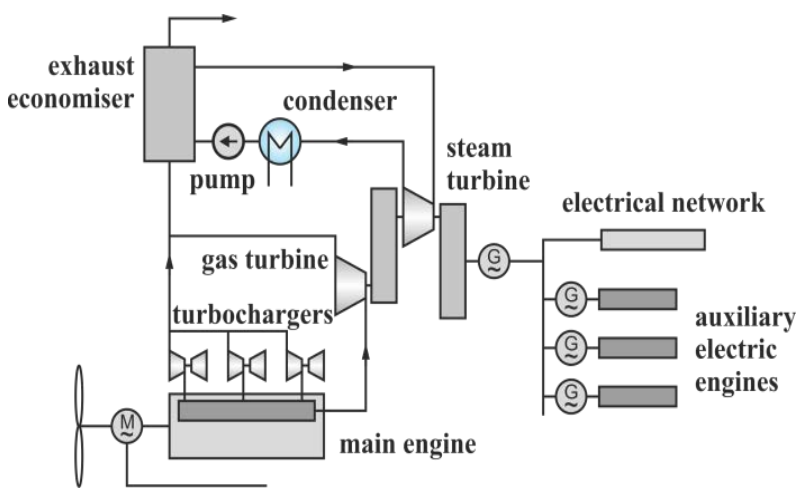

Fig. 1. An exemplary scheme of a ship's power plant with the utilization system of exhaust waste heat [1].

\footnotetext{
${ }^{*}$ Corresponding author: andrzej.stachel $@$,zut.edu.pl
} 


\section{Waste heat sources in the naval power plant}

Internal combustion engines used as the main propulsion of ships, are characterized by about $50 \%$ efficiency in the use of chemical energy in the fuel. Apart from the produced useful mechanical energy, significant rates of the so-called waste heat contained in various heat carriers are released to the surroundings.

The basis for determining the waste energy resources is the thermal balance of the engine being a combination of energy flows supplied in the fuel $\left(q_{d}\right)$ and produced work $\left(L_{u}\right)$ as well as the sum of individual losses $\left(\Sigma q_{s}\right)$ :

$$
q_{d}=L_{u}+\sum q_{s}
$$

where:

$$
q_{s}=q_{c}+q_{w}+q_{t}+q_{o d}+q_{p d}+q_{d}+q_{o s}+q_{s w}+q_{r}
$$

Heat losses are associated with cooling of cylinder heads and cylinder sleeves $\left(q_{c}\right)$, injectors $\left(q_{w}\right)$, pistons $\left(q_{t}\right)$, charge air $\left(q_{p d}\right)$, turbochargers $\left(q_{d}\right)$ and engine lubricating oil $\left(\mathrm{q}_{o s}\right)$ and finally the turbochargers $\left(q_{o d}\right)$. They also include exit losses $\left(q_{s w}\right)$ and the so-called the residual losses $\left(q_{r}\right)$, which include the losses due to radiation.

The extent of individual balance terms are variable and depend, among others, on the engine load (developed power), rotational speed, fuel type and ambient conditions as well as on the design and used cooling fluids. The real balances for specific engine types, provided by the manufacturers, are the basis for calculating the motor and ship related equipment and installations [1].

In the Figures 2 and 3 are presented, developed on the basis of catalog data [2], simplified heat balances of low-speed piston engines manufactured by MAN D\&T, as well as the values of basic temperatures of waste energy carriers, with the specification of minimum and maximum values. The graphs show that the main source of waste energy on the ship power plants are exhaust emissions from the main engine, both due to the amount of energy contained in them as well as their quality.

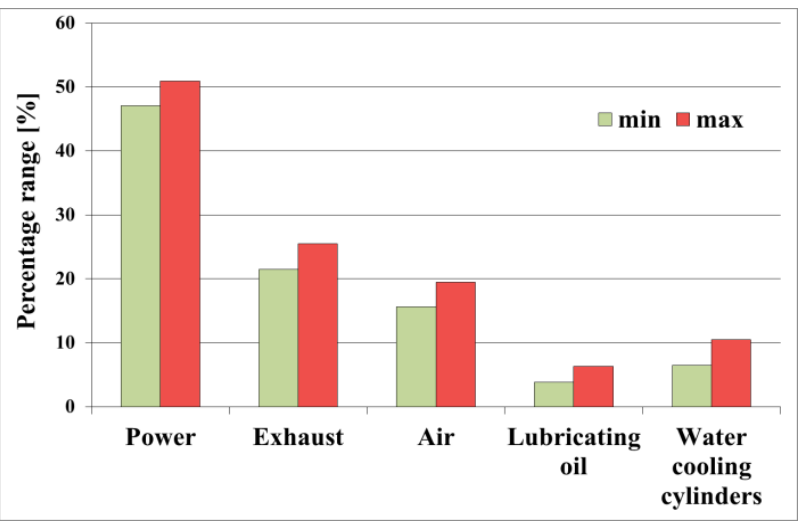

Fig. 2. Average percentage shares of power and rates of waste heat in low-speed engines (minimum - maximum values) [2].
It should be noted, however, that the introduced constructional and operational changes of the engines (e.g. larger piston stroke, increase of the boost pressure, lowering the rotational speed, etc.) affect the reduction of some waste energy streams (e.g. exhaust gases), while increasing others (e.g. air recharging).

In practice, not all available waste energy is valuable for further use. Its rate should be adequately large, and the temperature, pressure and mass flow of the heat carrier (e.g. exhaust gases) are of decisive importance. Knowledge of these values allows to determine the amount of energy and exergy of exhaust gases in individual places of the disposal system. Thus, it allows to make a rational decision regarding the selection of one of many possible variants of the waste energy utilization system.

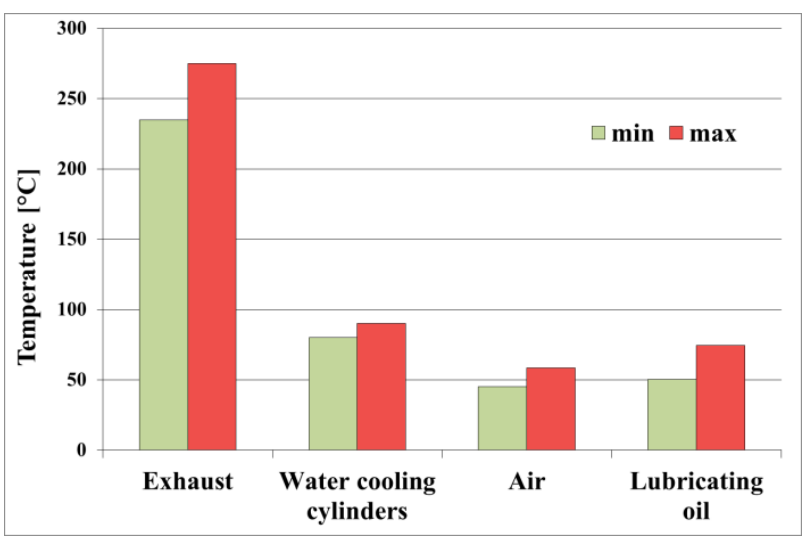

Fig. 3. Average ranges of temperatures of waste heat energy carriers in low-speed main engines (minimum - maximum values) [2].

In the case of internal combustion engines, a significant impact on the thermal parameters of the exhaust gas has the engine load related to the size of the generated power and the speed of rotation. It is also influenced by a number of other factors, such as the type of speed controller, which is related to, among others, the type of propeller (the propeller with a fixed or adjustable pitch). Examples of temperature changes $\left(\Delta T_{s}\right)$ and rate of exhaust gas $\left(\Delta \dot{m}_{s}\right)$ resulting from the change of engine load in the engine type L70MC-C are shown in Figure 4 and Figure 5.

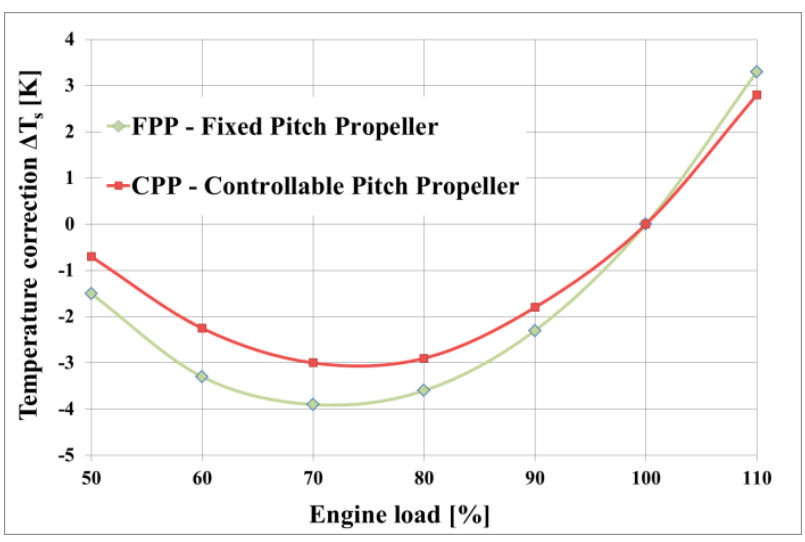

Fig. 4. Changes in exhaust gases temperature in relation to the engine load [3]. 
The operating loads of main engines (engine power) correspond usually to $85-90 \%$ of the so-called contractual power, and the corresponding rotational speed is $95-97 \%$ of the contractual speed, respectively. It can be seen from the graphs that the correct design of utilization systems requires consideration of various engine operating states, including those corresponding to partial loads in a wide range, thus taking into account the relevant parameters of exhaust gases.

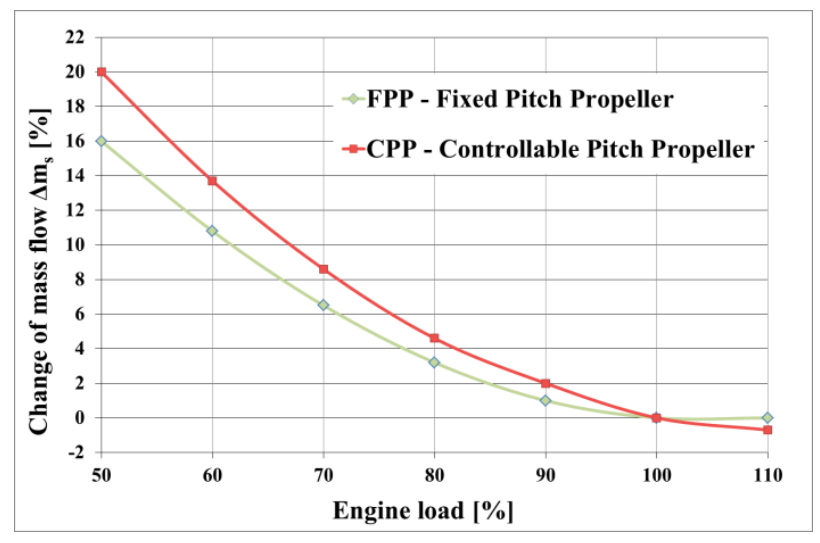

Fig. 5. Changes in exhaust gases mass flow rates in relation to the engine load [3].

Fig. 6 shows exemplary flue gas temperature changes, respectively for behind the engine cylinders and in the collectors before and after the turbochargers, depending on the load of the ship piston diesel engine.

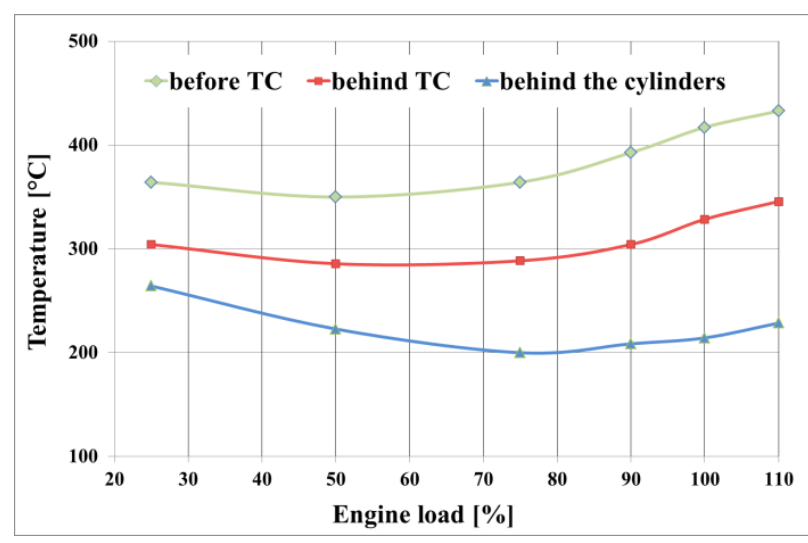

Fig. 6. Changes of exhaust gas temperatures behind cylinders and in collectors before turbochargers and after turbochargers, as a function of load of the engine 6L70MC [2].

\section{Ways of utilizing waste heat on ships}

The demand by the modern ships for various forms of energy (electric, heat and other), determined in relation to the main propulsion capacity, reaches values up to $40 \%$ for reefers, up to $25 \%$ for container vessels, up to $15 \%$ for bulk carriers, and depends on the period from their commissioning as well as the technical condition [4]. Some of these needs may be covered from waste energy sources.

Analyzing the solutions of modern marine combustion power plants, one can distinguish the main waste energy utilization systems used for:
- meeting the ship's heating demand,

- meeting electrical power demand,

- supporting the main propulsion of the ship,

- production of fresh water from sea water,

- meeting the cooling demand and others.

In the vast majority of power plants, the effect of waste energy utilization is useful heat, electricity and freshwater produced in evaporators. The easiest way - is to use that energy in the so called utilization boilers of steam / hot water for heating purposes. The waste energy used for this purpose is most often the heat from the exhaust gases from the motors.

Due to the development in recent years of so-called low-temperature power plant technology, one of the concepts of utilizing the waste energy from the main engine of the ship assumes the generation of electricity in the so-called ORC power plant working with the organic working fluid $[5,6]$. The operating principle of the ORC power plant is based on the classic comparative cycle of the steam water power plant ( $\mathrm{C}-\mathrm{R}$ cycle). The essential difference is the thermodynamic fluid used in circulation, which instead of water is a low-boiling organic substance.

\section{The concept of using waste heat from engine in ORC installation}

Analysis of the possibilities of using the ORC installation was related to the MAN D\&T L70MC-C8TII marine engine [3]. It is a low-speed, two-stroke, 6cylinder, in-line combustion engine, with mechanical control of the camshaft. The cylinder diameter is 700 $\mathrm{mm}$, whereas the piston stroke is $2360 \mathrm{~mm}$.

Depending on the size of the ratio of piston stroke to cylinder diameter, it is built in two variants marked first with the symbol L-MC (mean stroke, $\mathrm{S} / \mathrm{D}=3.2$ ) and secondly as $\mathrm{S}-\mathrm{MC}-\mathrm{C}$ (long stroke $\mathrm{S} / \mathrm{D}=4.0$ ). The engine is used as a main drive on ships such as container ships, tankers, bulk carriers and gas carriers. It can be powered with light fuel oil and heavy fuel oil (HFO). Selected basic engine operating parameters, determined at the socalled standard operating conditions (air temperature $25^{\circ} \mathrm{C}$, pressure $100 \mathrm{kPa}$, humidity $30 \%$ ), are given in the Table 1.

Table 1. Standard operation conditions of the combustion engine 6L70MC-C8 [3].

\begin{tabular}{|l|c|c|}
\hline Parameter & Unit & Value \\
\hline Engine power & $\mathrm{kW}$ & 19.620 \\
\hline Revolutions of the engine & $\mathrm{min}^{-1}$ & 108 \\
\hline Piston velocity & $\mathrm{m} / \mathrm{s}$ & $8,3-8,5$ \\
\hline Mean useful pressure & $\mathrm{bar}$ & 19.0 \\
\hline $\begin{array}{l}\text { Temperature of cooling water } \\
\text { at the engine inlet }\end{array}$ & ${ }^{\circ} \mathrm{C}$ & $32-36$ \\
\hline $\begin{array}{l}\text { Temperature of cooling water } \\
\text { at the engine outlet }\end{array}$ & ${ }^{\circ} \mathrm{C}$ & $80-90$ \\
\hline Flow rate of cooling water & $\mathrm{m}^{3} / \mathrm{h}$ & 155 \\
\hline $\begin{array}{l}\text { Temperature of exhaust gases } \\
\text { including the turbocompressor }\end{array}$ & ${ }^{\circ} \mathrm{C}$ & 265 \\
\hline Mass flowrate of exhaust gases & $\mathrm{kg} / \mathrm{s}$ & 44,5 \\
\hline
\end{tabular}




\subsection{ORC power plant supplied from the exhaust gases}

A simplified diagram of the ship engine system - ORC power plant is shown in Fig. 7. The installation consists of a heat exchanger, turbine with a generator, condenser and a circulating pump. The source of heat is the rate of exhaust gases leaving the engine available at temperature $T_{s 1}$, supplied to the heat exchanger (evaporator - heater), where the thermal energy contained in them is transferred to the working fluid in the ORC system, causing its heating to saturation conditions and subsequent evaporation. This results in the use of heat contained in the flue gases, and thus a decrease in their temperature (enthalpy), and as a result in a reduction of the exit losses. The exhaust gases, after giving away a part of the thermal energy contained in them, are discharged into the environment. Due to their relatively high thermodynamic potential, they still can be used for other purposes.

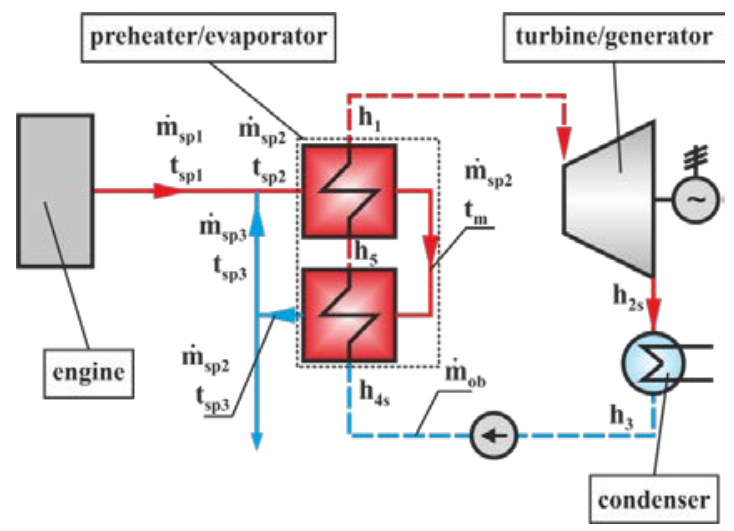

Fig. 7. Schematic of ORC system with an evaporator preheater heat exchanger, using a reversal of the part of the exhaust gases rate of heat.

In the considered variant of the power plant, implemented is the reversal of the part of the exhaust gases from behind the exchanger (heater) to the inlet to the exchanger (evaporator). This allows to regulate the temperature of the exhaust gas supplied to the evaporator, so as to obtain the assumed temperature difference between the heating fluid (exhaust gas) and the operating fluid in the ORC system. This is of great importance in the case when the temperature of exhaust gases is changing, resulting from changes in the load of the engine.

The saturated or superheated vapour produced in the evaporator (depending on the operating conditions and the working fluid used) - it is directed to the turbine, where it expands and generates work used to drive the electric generator. The vapour after expansion in the turbine flows to the condenser, where it condenses. The condensed liquid is pumped back into the heater evaporator assembly of heat exchangers.

\subsection{Methodology of calculations}

In order to determine the possibility of conversion of exhaust energy into the useful one (electric) in the ORC plant, the calculations of basic quantities characterizing its operation (power, efficiency) were made using the methodology given below.

The power plant capacity is defined as the difference in the work of the expansion of the working fluid in the turbine $L_{t}$ and the work of pumping in the pump $L_{p}$ :

$$
N_{C-R}=\dot{L}_{t}-\dot{L}_{p}
$$

where the work of expansion and work of pump can be expressed as products of the mass flow rate of working fluid in circulation $\left(\dot{m}_{O R C}\right)$ and corresponding enthalpy changes:

$$
\begin{aligned}
& L_{t}=\dot{m}_{n}\left(h_{1}-h_{2 s}\right) \\
& L_{p}=\dot{m}_{n}\left(h_{4}-h_{3}\right)
\end{aligned}
$$

In the case of the ORC power plant, depending on the working fluid and pressures resulting from the operational temperature of the cycle, the pumping work may constitute up to $15 \%$ of the work generated in the turbine.

The thermal efficiency of the power plant (C-R cycle) is defined by the relation:

$$
\eta_{C-R}=\frac{\dot{L}_{t}-\dot{L}_{p}}{\dot{Q}}
$$

where $\dot{Q}_{d}-$ heat supplied to the cycle:

$$
\dot{Q}_{d}=\dot{m}_{n}\left(h_{1}-h_{4}\right)
$$

Heat removed from the cycle in the condenser:

$$
\dot{Q}_{w}=\dot{m}_{n}\left(h_{2 s}-h_{3}\right)
$$

Electric power generated in the ORC power plant is defined by the formulae:

$$
N_{e l}=N_{C-R} \cdot \eta_{m} \cdot \eta_{g} \cdot \eta_{i}
$$

In order to determine the above quantities, the following values were determined:

- from the energy balance for the heat exchanger - mass flow rate of working fluid circulating in the power plant cycle:

$$
\dot{m}_{n}=\frac{\dot{m}_{s p 2} \cdot c_{s p} \cdot\left(t_{s p 2}-t_{s p 3}\right)}{h_{1}-h_{4 s}}
$$

- from the energy balance of exhaust gases - mass flow rate of exhaust gases flowing through the exchanger (evaporator - preheater):

$$
\dot{m}_{s p 2}=\frac{\dot{m}_{s p 1} \cdot\left(t_{s p 1}-t_{s p 3}\right)}{t_{s p 2}-t_{s p 3}}
$$

Utilizing the energy balance equations defined for the preheater (11) and the preheater - evaporator system (12): 


$$
\begin{aligned}
& \dot{m}_{s p 2} \cdot c_{s p} \cdot t_{m}+\dot{m}_{n} \cdot h_{4 s}=\dot{m}_{s p 2} \cdot c_{s p} \cdot t_{s p 3}+\dot{m}_{n} \cdot h_{5} \\
& \dot{m}_{s p 2} \cdot c_{s p} \cdot t_{s p 2}+\dot{m}_{n} \cdot h_{4 s}=\dot{m}_{s p 2} \cdot c_{s p} \cdot t_{s p 3}+\dot{m}_{n} \cdot h_{1}
\end{aligned}
$$

Determined was the temperature of exhaust gases leaving the heat exchangers (also that returning to the evaporator):

$$
t_{s p 3}=\frac{\Delta h \cdot t_{m}-t_{s p 2}}{\Delta h-1}, \text { where: } \Delta h=\frac{h_{1}-h_{4 s}}{h_{5}-h_{4 s}}
$$

In order to determine the values of the flow rate of exhaust gases from behind the preheater into the inlet of evaporator $\left(\dot{m}_{s p 3}\right)$, which enables obtaining of the assumed temperature difference between the exhaust gases and the circulation fluid in ORC system there has been used energy balance equation for the node „A":

$$
\dot{m}_{s p 1} \cdot c_{s p} \cdot t_{s p 1}+\dot{m}_{s p 3} \cdot c_{s p} \cdot t_{s p 3}=\dot{m}_{s p 2} \cdot c_{s p} \cdot t_{s p 2}
$$

and the mass flow rate balance:

$$
\dot{m}_{s p 2}=\dot{m}_{s p 1}+\dot{m}_{s p 3}
$$

In the calculations, it was assumed that the temperature of the flue gases at the evaporator inlet is $15 \mathrm{~K}$ higher, and on the evaporator outlet by $5 \mathrm{~K}$ from the circulating fluid evaporating temperature in the ORC power plant. An exemplary temperature distribution for the evaporator - heater unit is shown in the Fig. 8.

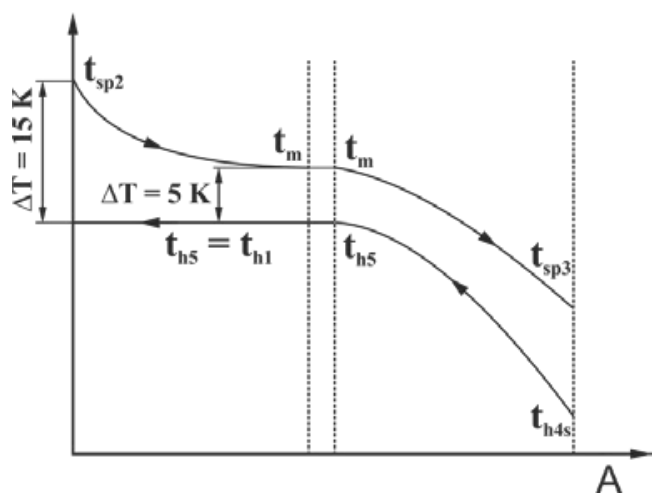

Fig. 8. Temperature distributions in the heat exchanger of the evaporator/preheater type in the ORC installation in case of dry fluids.

\subsection{Assumptions for calculations}

It was assumed that the considered ORC power plant operates in a subcritical cycle, and selected working fluids belong to the group of so-called dry fluids, which means that their isentropic expansion in the turbine, starting on the dry saturated vapour line, ends in the area of superheated vapour.

The selection of the working fluid, which can be used in the ORC system, depends on the temperature of the energy carrier (exhaust) and requires careful consideration, both due to the efficiency of the circulation work and the operational possibilities. The working fluid should be characterized by:
- appropriate thermal and physical properties,

- chemical stability at high temperatures,

- lack of harmful effects on the environment and elements of the installation.

In addition, in the case of ORC marine installations, the working fluid should meet the operational safety requirements, in particular its non-flammability. This condition quite significantly limits the number of substances that can be used in the marine ORC power plant.

Detailed recommendations for selection of working fluids and the requirements set for them are discussed in numerous works on the ORC power plants $[5,6,7]$.

Taking the above into consideration, five working fluids from the group of dry substances were assumed for the analysis, namely: R245fa (1,1,1,3,3-pentafluoropropane, $\mathrm{CF}_{3} \mathrm{CH}_{2} \mathrm{CHF}_{2}$ ); perfluoropentane (dodecafluoro-pentane, $\quad \mathrm{C}_{5} \mathrm{~F}_{12}$ ); $\mathrm{R} 123$ (2,2-dichloro-1,1,1trifluoro-ethane, $\mathrm{CHCl}_{2} \mathrm{CF}_{3}$ ) (Table 2).

Table 2. Selected organic working fluids and their fundamental parameters [8].

\begin{tabular}{|c|c|c|c|c|c|}
\hline \multirow{2}{*}{$\begin{array}{c}\text { Working } \\
\text { fluid }\end{array}$} & $\begin{array}{c}\text { Molar } \\
\text { mass }\end{array}$ & \multicolumn{2}{|c|}{$\begin{array}{c}\text { Range of } \\
\text { applicability }\end{array}$} & \multicolumn{2}{c|}{ Critical point } \\
\cline { 2 - 6 }$[\mathrm{kg} / \mathrm{kmol}]$ & $\begin{array}{c}\mathrm{T}_{\min } \\
{\left[{ }^{\circ} \mathrm{C}\right]}\end{array}$ & $\begin{array}{c}\mathrm{T}_{\max } \\
{\left[{ }^{\circ} \mathrm{C}\right]}\end{array}$ & $\begin{array}{c}\mathrm{T}_{\mathrm{kr}} \\
{\left[{ }^{\circ} \mathrm{C}\right]}\end{array}$ & $\begin{array}{c}\mathrm{P}_{\mathrm{kr}} \\
{[\mathrm{MPa}]}\end{array}$ \\
\hline $\mathrm{R} 245 \mathrm{fa}$ & 134,05 & $-102,1$ & 166,85 & 154,01 & 3,651 \\
\hline $\begin{array}{c}\text { Perfluoro- } \\
\text { pentane }\end{array}$ & 288,03 & $-124,8$ & 226,85 & 147,41 & 2,045 \\
\hline R123 & 152,93 & $-107,1$ & 326,85 & 183,68 & 3,662 \\
\hline
\end{tabular}

An important element of the analysis of the operation of ORC installation under consideration is the determination of evaporating temperature of the working fluid depending on the temperature of the exhaust gas supplied to the evaporator. The temperature of the exhaust depends on the main engine operating parameters, that is on its load and exhibits serious fluctuations within relatively large limits. In order to ensure stable operation of the ORC plant, it was assumed that the power plant is supplied with a constant temperature flue gases at the inlet to the evaporator, which was obtained by returning parts of the cooled exhaust gases leaving the exchanger and mixing them with fresh exhaust gases supplied from the engine.

Data describing mass flow rates and flue gas temperatures as a function of 6L70MC-C main engine load, determined on the basis of relations given in the manufacturer's catalog [3], are presented in the Table 3 .

Table 3. Exhaust gas parameters assumed for calculations which result from the load of the main engine.

\begin{tabular}{|c|c|c|c|c|c|}
\hline \multirow{2}{*}{$\begin{array}{c}\text { Engine } \\
\text { load }\end{array}$} & \multirow{2}{*}{$\begin{array}{c}\text { Engine } \\
\text { power }\end{array}$} & $\Delta \mathrm{m}_{\%}$ & $\Delta \mathrm{T}_{\mathrm{M}}$ & $\mathrm{M}_{\mathrm{sp}}$ & $\mathrm{T}_{\mathrm{sp}}$ \\
\cline { 3 - 6 } & {$[\%]$} & ${ }^{\circ} \mathrm{C}$ & $\mathrm{kg} / \mathrm{s}$ & ${ }^{\circ} \mathrm{C}$ \\
\hline 0,60 & 11772 & 5.11 & -30.65 & 30.80 & 214.35 \\
\hline 0,65 & 12753 & 4.31 & -25.85 & 33.11 & 219.15 \\
\hline 0,70 & 13734 & 3.57 & -21.40 & 35.40 & 223.60 \\
\hline 0,75 & 14715 & 2.88 & -17.26 & 37.68 & 227.74 \\
\hline
\end{tabular}


Table 3: continuation.

\begin{tabular}{|c|c|c|c|c|c|}
\hline 0,80 & 15696 & 2.23 & -13.39 & 39.94 & 231.61 \\
\hline 0,85 & 16677 & 1.63 & -9.75 & 42.18 & 235.25 \\
\hline 0,90 & 17658 & 1.05 & -6.32 & 44.41 & 238.68 \\
\hline 0,95 & 18639 & 0.51 & -3.08 & 46.63 & 241.92 \\
\hline 1,00 & 19620 & 0.00 & 0.00 & 48.83 & 245.00 \\
\hline
\end{tabular}

\section{Results of calculations}

Calculations of the ORC power plant have been made for different values of mass flow rates and different exhaust temperatures, resulting from the main ship engine (its load) generated power. The extent of the mass flow rates and temperature were determined on the basis of the relations given in the manufacturer's catalog materials the MAN D\&T [3].

Values of enthalpy of the working fluid, necessary for calculating the individual states of the ORC cycle, specified for the assumed temperature and evaporating pressure, were determined on the basis of the Refprop 9.1 database (Table 4) [8].

Table 4. Enthalpy values for selected working fluids in characteristic points of the ORC cycle (for $\mathrm{T}_{\mathrm{par}}=140^{\circ} \mathrm{C}$ ).

\begin{tabular}{|c|c|c|c|c|}
\hline $\begin{array}{c}\text { Working } \\
\text { fluid }\end{array}$ & & R245fa & $\begin{array}{l}\text { Perfluoro- } \\
\text { pentane }\end{array}$ & R123 \\
\hline $\mathrm{P}_{\mathrm{par}}$ & $\mathrm{MPa}$ & 2,8287 & 1,7690 & 1,7563 \\
\hline $\mathrm{h}_{1}$ & \multirow{5}{*}{$\mathrm{kJ} / \mathrm{kg}$} & 488,59 & 168,27 & 457,94 \\
\hline $\mathrm{h}_{2 \mathrm{~s}}$ & & 439,41 & 141,99 & 410,70 \\
\hline $\mathrm{h}_{3}$ & & 239,10 & 0,27 & 230,26 \\
\hline $\mathrm{h}_{4 \mathrm{~s}}$ & & 241,11 & 1,31 & 231,39 \\
\hline $\mathrm{h}_{5}$ & & 409,80 & 136,75 & 353,92 \\
\hline
\end{tabular}

The sample results of the ORC plant calculations related to the nominal engine operation parameters $(100 \%$ load) and selected working fluids are presented in Table 5. The calculations were made taking into account the nominal power $\mathrm{N}_{\text {nom }}=1962 \mathrm{~kW}$, rotational velocity $\mathrm{n}_{\text {nom }}=108 \mathrm{rpm}$ and mass flow rate flue gases $\mathrm{m}_{\text {nom }}=48.83 \mathrm{~kg} / \mathrm{s}$.

The results of calculations made for the whole analyzed range of loads of the main engine and considered working fluids are presented graphically in the following figures. In the Fig. 9 presented is the attainable extent of power, whereas in Fig. 10 the values of thermodynamic efficiency of the Clausius-Rankine cycle. It stems from these graphs that for the assumptions set out in the work, in case when the engine was operated with the nominal load, the highest power was obtained when using R245fa as the working fluid, and the lowest one in case of considering the fluid named as perfluoropentane. At partial loads of the motor, the ORC power is correspondingly lower and shows an increasing trend as the load increases. The lowest values of thermodynamic efficiency of the Clausius-Rankine cycle were observed for perflupropentane, while the highest values for R123, where in the system under consideration for each of these working fluids, these values are constant, regardless of the engine load.

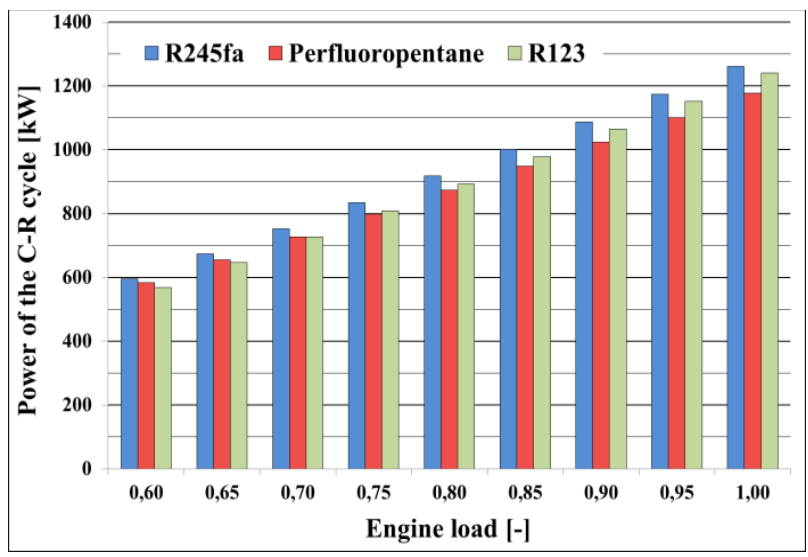

Fig. 9. The power of the C-R cycle in function of the engine load, for selected working fluid.

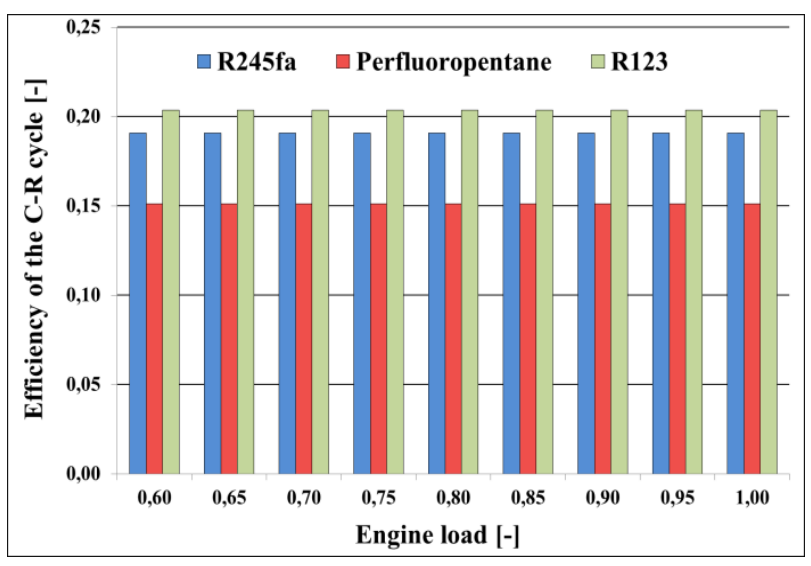

Fig. 10. Efficiency of the C-R cycle in function of main engine load, for selected working fluids.

Table 5. Results of calculation of the ORC system supplied with heat of flue gases from the 6L70MC-C engine (operation with nominal power).

\begin{tabular}{|c|c|c|c|c|c|c|c|c|c|c|c|c|}
\hline Working & $t_{\mathrm{sp} 1}$ & $t_{\mathrm{sp} 2}$ & $t_{\mathrm{sp} 3}$ & $t_{\mathrm{m}}$ & $\mathrm{m}_{\mathrm{sp} 1}$ & $\mathrm{~m}_{\mathrm{sp} 2}$ & $\mathrm{~m}_{\mathrm{sp} 3}$ & $\mathrm{~m}_{\mathrm{ob}}$ & $\mathrm{N}_{\mathrm{OR}}$ & $\eta_{C-R}$ & $\mathrm{~N}_{\mathrm{el}}$ & $\eta_{\mathrm{el}}$ \\
\hline fluid " & ${ }^{\circ} \mathrm{C}$ & ${ }^{\circ} \mathrm{C}$ & ${ }^{\circ} \mathrm{C}$ & ${ }^{\circ} \mathrm{C}$ & $\mathrm{kg} / \mathrm{s}$ & $\mathrm{kg} / \mathrm{s}$ & $\mathrm{kg} / \mathrm{s}$ & $\mathrm{kg} / \mathrm{s}$ & $\mathrm{kW}$ & $\%$ & $\mathrm{~kW}$ & $\%$ \\
\hline R245fa & \multirow{3}{*}{245,00} & \multirow{3}{*}{155} & 123,59 & \multirow{3}{*}{145} & \multirow{3}{*}{48,83} & 188,76 & 139,92 & 26,74 & 1261,13 & 19,1 & 880,78 & 13,3 \\
\hline Perfluoropentane & & & 102,03 & & & 131,81 & 82,97 & 46,67 & 1177,82 & 15,1 & 822,59 & 10,6 \\
\hline R123 & & & 133,22 & & & 250,63 & 201,80 & 26,89 & 1239,86 & 20,4 & 865,92 & 14,2 \\
\hline
\end{tabular}

*) R245fa: 1,1,1,3,3-pentafluoropropane; Perfluoropentane: dodecafluoropentane; R123: 2,2-dichloro-1,1,1-trifluoroethane 
Fig. 11 contain the results of calculations of the electric power that can be generated in the ORC plant are shown, for the case of various fluids considered in the analysis and for different loads of the main engine. In the calculations, the following efficiencies were assumed: turbine $\eta_{\mathrm{i}}=0.75$, mechanical $\eta_{\mathrm{m}}=0.97$ and electric generator $\eta_{\mathrm{g}}=0.96$

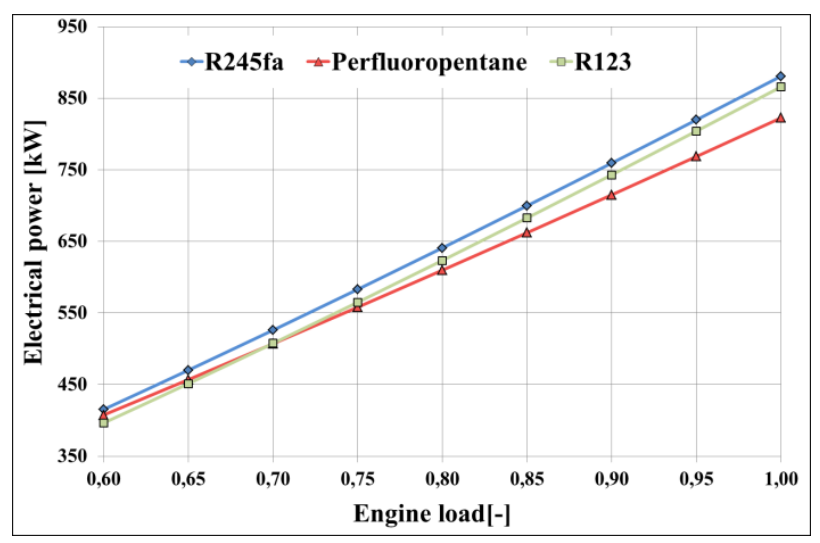

Fig. 11. Generated electric power in the ORC power plant powered by the exhaust gases from a marine engine (as a function of engine load, for selected working fluids).

\section{Conclusions}

The presented analysis is a part of the work carried out by the authors, regarding the use of the ORC power plant to generate electricity using low-temperature heat sources, including waste energy sources.

The obtained results of calculations show that there is a real possibility of using waste heat from the marine engine to power the low-temperature ORC power plant. They also show that the type of selected working fluid and the thermal parameters of the exhaust gases, resulting from the operation of the ship engine, have a significant impact on the energy effect of the plant operation.

The power generated by the ORC plant, defined as the power of the C-R cycle, at nominal load of the main engine, reaches the value of $1177.82 \mathrm{~kW}$ (for the working fluid perfluoropentane) to $1261,13 \mathrm{~kW}$ (for R245fa), which corresponds to 6,00 up to $6,43 \%$ of the nominal engine power. On the other hand, the plant efficiency defined as the efficiency of the C-R cycle varies from $15.1 \%$ (perfluoropentane) to $20.4 \%$ (R123).

The theoretical electric power of the ORC plant obtained in the calculations achieves, depending on the working fluid, the value from $822.59 \mathrm{~kW}$ to $880.78 \mathrm{~kW}$, which constitutes from 4.19 to $4.49 \%$ of the nominal power of the main engine. The powers indicated above relate to the operation of the engine with nominal load. When operating with a partial load, the attainable powers are correspondingly smaller.

Summarizing, it can be concluded that the use of the ORC installation supplied with heat from the exhaust gases from the main marine engine allows for generation of additional electricity and thus improves the energy efficiency of the ship's engine.

\section{References}

1. A. Balcerski, Ship power plants: thermodynamics bases, engines and main drives, auxiliary devices, installations (Gdańsk University of Technology Publishing House, Gdańsk, 1986, in Polish)

2. R. Michalski, W. Zeńczak, S. Żmudzki, Selected problems of energy conversion technology in marine energy systems (Kaprint, Lublin, 2012, in Polish).

3. MAN B\&W L70MC-C8-TII Project Guide Camshaft Controlled Two-Stroke Engines (MAN Diesel \& Turbo, Copenhagen, Denmark, 2010).

4. C. Behrend, Problems of determining and using waste heat resources in marine energy systems. Scientific Journals of the Polish Naval Academy, 10 (82) pp. 31-40 (2006, in Polish).

5. P. Weisser, P. Skotnicki, Perspectives of using ORC systems for low temperature waste energy. Publisher: Instytut Śląski (2010)

6. R. DiPippo, Geothermal power plants. Principles, applications, case studies and environmental impact (Elsevier, Amsterdam, 2008)

7. W. Nowak, A. Borsukiewicz-Gozdur, P. Klonowicz, A. Stachel, P. Hanausek, W. Klonowicz, Preliminary results of testing the prototype system of mini-water plants with ORC fed with water at $100^{\circ}$ C. Geological Rev. 58, 7 (2010).

8. Refprop 9.1 Standard Reference Database 23, Version 9.1, Reference Fluid Thermodynamic and Transport Properties. National Institute of Standarts and Technology (Gaithersburg, USA, 2013).

\section{Nomenclature}

$\begin{array}{lll}c_{w} & \text { specific heat capacity } & \mathrm{kJ} /(\mathrm{kgK}) \\ h & \text { specific enthalpy } & \mathrm{kJ} / \mathrm{kg} \\ \dot{m} & \text { mass flow rate } & \mathrm{kg} / \mathrm{s} \\ N & \text { power } & \mathrm{kW} \\ \dot{Q} & \text { heat flow } & \mathrm{kW} \\ t & \text { temperature } & { }^{\circ} \mathrm{C} \\ \eta & \text { efficiency } & \%\end{array}$

\section{Subscripts:}

$C R \quad$ refers to the Clausius-Rankine cycle

el refers to the power plant

$n \quad$ refers to the working medium

$p \quad$ refers to the pump

$s \quad$ refers to geothermal water (heating water)

sp refers to the exhaust gases

$t \quad$ refers to a turbine

$1,2 s, . . \quad$ refers to the characteristic points of the CR cycle 